\title{
Oxidative/antioxidative status, lymphocyte DNA damage, and urotensin-2 receptor level in patients with migraine attacks
}

This article was published in the following Dove Press journal:

Neuropsychiatric Disease and Treatment

\author{
Mehmet Yigit \\ Ozgur Sogut ${ }^{\prime}$ \\ Özlem Tataroglu' \\ Adnan Yamanoglu' \\ Eda Yigit ${ }^{2}$ \\ Eray Metin Güler ${ }^{3}$ \\ Omer Faruk Ozer ${ }^{3}$ \\ Abdurrahim Kocyigit ${ }^{3}$ \\ 'Department of Emergency Medicine, \\ Haseki Training and Research Hospital, \\ University of Health Sciences, \\ 2Department of Emergency Medicine, \\ Sisli Hamidiye Etfal Training and \\ Research Hospital, University of \\ Health Sciences, ${ }^{3}$ Department of \\ Biochemistry, Faculty of Medicine, \\ Bezmialem Vakif University, Istanbul, \\ Turkey
}

Background: The present study investigated the potential roles of plasma lymphocyte DNA damage, the urotensin-2 receptor (UTS2R), and oxidative changes in patients with varying degrees of migraine-related disability who were in the ictal phase and presented to our emergency department.

Methods: This study enrolled 40 consecutive adult patients with migraine attack and 40 age- and sex-matched healthy controls. The same health care professional determined the headache-related disability of each patient's migraine attack using the Migraine Disability Assessment Scale (MIDAS); patients were divided into three groups based on MIDAS score. Plasma lymphocyte DNA damage; UTS2R, malondialdehyde (MDA), and catalase (CAT) levels; total oxidant status (TOS); total antioxidant status (TAS); and the oxidative stress index (OSI) were used as predictors of early oxidative changes.

Results: Plasma lymphocyte DNA damage, TOS, MDA levels, and OSI values were significantly higher in patients with migraine compared to controls. Conversely, TAS and CAT and UTS2R levels were markedly lower in patients with migraine compared to controls. Comparisons of the patient groups by MIDAS score revealed significant differences in plasma lymphocyte DNA damage and CAT levels but no differences in TOS, MDA levels, OSI, TAS, or UTS2R levels. MIDAS scores were positively correlated with the degree of lymphocyte DNA damage, but neither of these factors was significantly related to CAT levels.

Conclusion: The present data suggest that lymphocyte DNA damage and changes in oxidative/ antioxidative status may reflect an enhanced oxidative damage and an ineffective antioxidant defense system in migraineurs during headache attacks. In addition, lymphocyte DNA damage levels may be an indicator of the degree of migraine-related disability as assessed by MIDAS score.

Keywords: migraine attack, oxidative/antioxidative changes, lymphocyte DNA damage, urotensin-2 receptor, Migraine Disability Assessment Scale

\section{Introduction}

Oxidative stress is an imbalance between the production of reactive oxygen species (ROS) and their elimination by antioxidants. ${ }^{1}$ ROS include endogenous factors such as hydroxyl $(\mathrm{OH})$ radicals, superoxide anions, hydrogen peroxide $\left(\mathrm{H}_{2} \mathrm{O}_{2}\right)$, and nitric oxide, which can lead to oxidative damage in DNA, lipids, and proteins. When ROS generation increases to the extent that ROS overcomes cellular antioxidants, the result is oxidative stress., ${ }^{2,3}$ Oxidative stress-induced acute inflammatory responses may play an important role in the pathogenesis of acute pain arising from migraine. ${ }^{4-6}$ The migraine threshold of an individual depends on the balance between stimulation
Department of Emergency Medicine Haseki Training and Research Hospital, University of Health Sciences, Millet Street, Zip Code: 34096, Fatih/Istanbul, Turkey

Tel +902123128456 ext 2406

$\mathrm{Fax}+902123139615$

Email ozgur.sogut@sbu.edu.tr
Neuropsychiatric Disease and Treatment 2018:14 367-374

367

Dovepress f $y$ in 0

http:!/dx.doi.org/10.2147/NDTS156710 (c) (1) (5) 2018 Yigit et al. This work is published and licensed by Dove Medical Press Limited. The full terms of this license are available at https://www.dovepress.com/terms.php cc) ${ }_{\mathrm{BY}} \mathrm{NC}$ and incorporate the Creative Commons Attribution - Non Commercial (unported, v3.0) License (http://creativecommons.org/licenses/by-nc/3.0/). By accessing the work you hereby accept the Terms. Non-commercial uses of the work are permitted without any further permission from Dove Medical Press Limited, provided the work is properly attributed. For permission for commercial use of this work, please see paragraphs 4.2 and 5 of our Terms (https://www.dovepress.com/terms.php). 
and inhibition in the central nervous system via oxidative phosphorylation in mitochondria. ${ }^{7,8}$ Endothelin- 1 is a potent vasoconstrictor that may mediate the vasoconstrictor phase of migraine attacks. ${ }^{9}$ The urotensin- 2 receptor (UTS2R) is a vasoactive somatostatin-like cyclic peptide found in vascular and cardiac tissue. ${ }^{10}$ This peptide has a more potent effect on vasoconstriction than endothelin-1, and its levels are significantly higher in patients with migraine without aura. ${ }^{10,11}$

Although previous studies have shown that oxidative changes impact patients with migraine, the findings of clinical reports assessing oxidative stress in migraine patients remain controversial. . $5,6,8,12$ Some studies have found a significant relationship between oxidative changes and migraine, ${ }^{1,8,13}$ whereas others have found no significant correlation., ${ }^{4,6,12}$ To the best of our knowledge, no case-control studies have simultaneously investigated UTS2R, oxidative stress parameters, and oxidative stress-related DNA damage in migraineurs with varying levels of headache-related disability during the ictal phase using Migraine Disability Assessment Scale (MIDAS) scores.

Thus, the present study aimed to determine plasma lymphocyte DNA damage, UTS2R levels, and oxidative changes in patients with migraine. Plasma lymphocyte DNA damage; UTS2R, malondialdehyde (MDA), and catalase (CAT) levels; total oxidant status (TOS); total antioxidant status (TAS); and the oxidative stress index (OSI), which are indicators of early oxidative changes, were assessed in migraine patients and then compared to a control group. In addition, we investigated whether lymphocyte DNA damage, UTS2R levels, and oxidative changes reflect the migrainerelated disability as assessed by MIDAS scores, which were calculated for each patient by a single health care professional upon patients' arrival in the emergency department (ED).

\section{Methods}

From August 2015 to January 2016, the present prospective case-control study enrolled 40 consecutive adult patients (14 males and 26 females; age range: $21-55$ years) who were admitted to our tertiary-care university hospital ED with a diagnosis of migraine attack; 40 age- and sex-matched healthy volunteers were also included in this study. Migraine was diagnosed according to patient history and the criteria of the Headache Classification Committee of the International Headache Society (IHS), third edition. ${ }^{14}$ Briefly, the IHS diagnostic criteria state that a patient must have had at least five headache attacks that lasted 4-72 h (untreated or unsuccessfully treated) and that the headache must have had at least two of the following characteristics: 1) unilateral location,
2) a pulsating quality, 3) moderate or severe pain intensity, or 4) aggravation by or causing avoidance of routine physical activity (eg, walking or climbing stairs). Upon arriving in the ED, each patient was assessed by the same health care professional using the MIDAS to assess the headache-related disability; the score was calculated using the questionnaire to determine the impact of migraine headaches on the patient's ability to function in work, home, and social situations. ${ }^{15}$ Subsequently, the patients were divided into three groups according to their MIDAS score: mild disability (MIDAS score: 6-10; MIDAS-II group), moderate disability (MIDAS score: 11-20; MIDAS-III group), and severe disability (MIDAS: >20; MIDAS-IV group).

The inclusion criteria were as follows: adult patients ( $\geq 18$ years) diagnosed with migraine who had not taken prophylactic treatment for at least 3 months and who had had a sympathomimetic drug-free period of at least $72 \mathrm{~h}$ prior to providing blood samples in the ictal phase. The exclusion criteria were as follows: conditions that may have affected oxidative markers, such as chronic medical disorders (ie, congestive heart failure, chronic obstructive lung disease, diabetes mellitus, coronary artery disease, peripheral vascular disease, chronic renal failure, stroke, hypertension, multiple sclerosis, Parkinson's disease, or malignancy); alcohol use, tobacco use, and/or Ecstasy use; being pregnant or exhibiting elevated human chorionic gonadotropin (hCG) levels detected by a quantitative hCG blood test ( $\beta$-hCG); and having undergone computed tomography and/or magnetic resonance imaging scans. None of the subjects were taking drugs known to affect lipid or lipoprotein metabolism, and special care was taken to exclude subjects who were taking anabolic drugs, diuretics, vitamins, or other antioxidants (such as vasoactive and beta-blocking agents).

The present study was conducted in accordance with the 1989 Declaration of Helsinki and was approved by the Ethics Committee of Bezmialem Vakif University, Faculty of Medicine. Written informed consent was obtained directly from patients after the migraine attack was controlled by medications. Furthermore, the healthy volunteers were informed about the study protocol, and written consent was obtained from all participants prior to their participation in the study.

\section{Blood sampling}

Upon admission, venous blood samples were drawn from the antecubital vein of each patient without the use of sympathomimetic migraine medications, collected into heparinized tubes, and immediately stored on ice at $4^{\circ} \mathrm{C}$. Plasma 
was separated from the blood samples by centrifugation at 4,000 rpm for $5 \mathrm{~min}$, and the plasma samples were stored at $-80^{\circ} \mathrm{C}$ until lymphocyte DNA damage; UTS2R, MDA, and CAT levels; TOS; TAS; and OSI were assessed.

\section{Measurement of UTS2R}

Plasma UTS2R levels were assessed using a human urotensin 2 enzyme-linked immunosorbent assay (ELISA) kit (SunRed Bio, Shanghai, People's Republic of China). Samples were thawed at room temperature, centrifuged at 3,000 rpm for $10 \mathrm{~min}$, and diluted to the appropriate concentrations; then an ELISA was performed according to the manufacturer's instructions. The supplied standards were used to generate standard curves. Next the samples and standards were added to the wells, unbound proteins were removed by washing, and the conjugate was added. After we performed a color reaction using a substrate, we recorded optical density using an automated ELISA reader at a wavelength of $450 \mathrm{~nm}$. The absorbance at $450 \mathrm{~nm}$ was converted into $\mathrm{ng} / \mathrm{mL}$ for urotensin 2; the minimal detection limit was $0.05 \mathrm{ng} / \mathrm{mL}$.

\section{Quantification of TOS}

Plasma TOS was analyzed using a novel automated measurement method developed by Erel. ${ }^{16}$ Oxidants that occur in serum oxidize the ferrous ions of O-dianisidine compounds to ferric ions. This oxidation results in the formation of ferric ions that are visualized as colored compounds in acidic circumstances using xylenol orange; the color density of xylenol orange is directly proportional to the oxidant level. In the present study, $\mathrm{H}_{2} \mathrm{O}_{2}$ was used to calibrate the assay. The results are expressed in terms of micromoles of $\mathrm{H}_{2} \mathrm{O}_{2}$ equivalent per liter $\left(\mu \mathrm{mol} \mathrm{H}_{2} \mathrm{O}_{2}\right.$ equiv/L). This assay has excellent precision values of $<2 \%$.

\section{Quantification of TAS}

Plasma TAS was measured using a fully automated colorimetric assay developed by Erel ${ }^{17}$ based on measurements of the amounts of $\mathrm{OH}$ radicals. $\mathrm{The}(\mathrm{Fe}+2+\mathrm{O}$-dianisidine) compound constitutes Fenton-type reactions with $\mathrm{H}_{2} \mathrm{O}_{2}$ to generate $\mathrm{OH}$ radicals that react with the $\mathrm{O}$-dianisidine molecules to form yellowish-brown dianisidine radicals. Existing antioxidants inhibit color formation by suppressing oxidant reactions. The reaction was performed using spectrophotometry at $240 \mathrm{~nm}$ with an automated analyzer (Architect CI16200; Abbott Laboratories, Abbott Park, IL, USA). Trolox, a water-soluble analog of vitamin E, was used as the calibrator. This assay determines the antioxidative capacity of the sample against potent free radical reactions triggered by the $\mathrm{OH}$ radical. In the present study, the results are expressed as millimoles of Trolox equivalent per liter millimole ( $\mathrm{mmol}$ Trolox equiv/L). The precision of the assay is $<3 \%$.

\section{OSI}

OSI is an indicator of the degree of oxidative stress. It is expressed as a percentage of the ratio of serum TOS to TAS and was calculated using the following formula: OSI $($ arbitrary unit $)=\left(\right.$ TOS,$\mu \mathrm{mol} \mathrm{H}_{2} \mathrm{O}_{2}$ eq/L) $/(\mathrm{TAS}, \mu \mathrm{mol}$ Trolox $\mathrm{eq} / \mathrm{L}) \times 10^{-1} \cdot{ }^{16}$

\section{Quantification of CAT}

CAT levels were assessed spectrophotometrically using a gasometric procedure that measures the volume of oxygen produced by the decomposition of $\mathrm{H}_{2} \mathrm{O}_{2}$. We determined CAT enzyme activity by measuring the decrease in $\mathrm{H}_{2} \mathrm{O}_{2}$ absorbance at $240 \mathrm{~nm}$ with a multiplate reader (Varioskan Flash Multimode Reader; Thermo Fisher Scientific, Waltham, MA, USA).

\section{Lipid peroxidation and measurement of MDA}

As an index of lipid peroxidation, we measured MDA levels in red blood cells using the method of Stocks et $\mathrm{al}^{18}$ and in plasma using the method of Ohkawa et al. ${ }^{19}$ Then, levels of pink chromogen produced by the reaction of thiobarbituric acid-reactive substances and other aldehydes were estimated.

\section{Assessment of lymphocyte DNA damage with the alkaline comet assay}

Human blood samples were collected by venipuncture from the antecubital vein $(\sim 5 \mathrm{~mL})$ of each patient and immediately transferred into tubes containing a sterile EDTA solution (EDTA Titriplex ${ }^{\circledR}$ III; SCM, Burlingame, CA, USA). Then $250 \mu \mathrm{L}$ of blood sample was transferred by pipette into an Eppendorf tube and kept in a refrigerator at $-80^{\circ} \mathrm{C}$ until analysis 4 weeks later, as described by Singh et $\mathrm{al}^{20}$ with minor modifications. Microscope slides were coated with $1.0 \%$ hot $\left(60^{\circ} \mathrm{C}\right)$ normal melting point agarose (NMA) prepared in phosphate-buffered saline and then covered with a coverslip at $4{ }^{\circ} \mathrm{C}$ for at least $5 \mathrm{~min}$ to allow the agarose to solidify. After the removal of the coverslips, a $5 \mu \mathrm{L}$ sample of whole blood was embedded in $0.7 \%$ low melting point agarose at $37^{\circ} \mathrm{C}$. Next, $85 \mu \mathrm{L}$ of this cellular suspension was spread onto slides that had previously been coated with NMA and then covered with a coverslip. The slides were allowed to solidify for $10 \mathrm{~min}$ at $4^{\circ} \mathrm{C}$ in a moist box. 


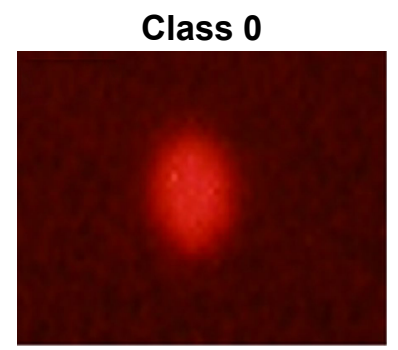

Class 3

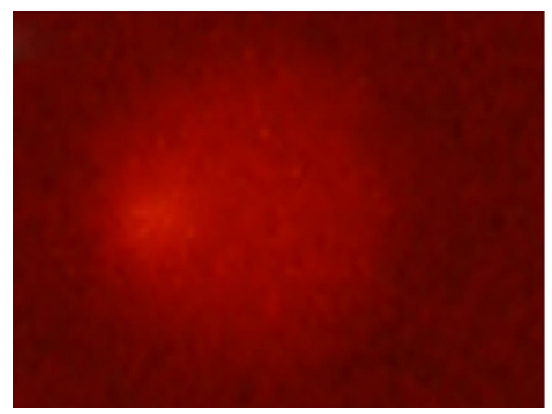

Class 2

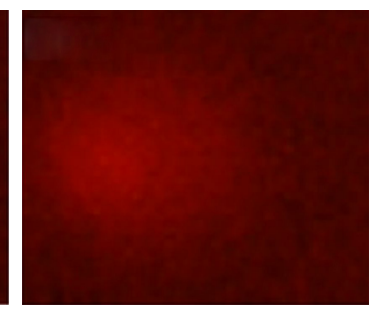

Class 4

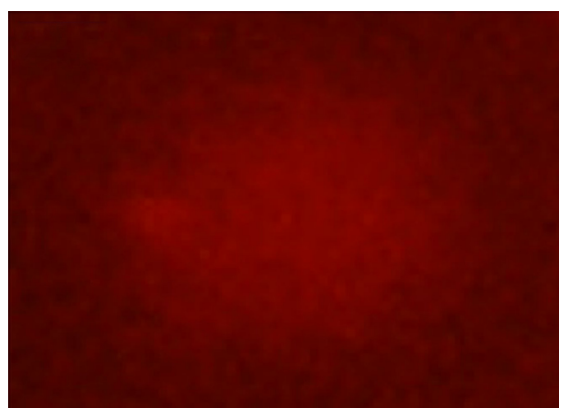

Figure I DNA damage in human lymphocytes assessed with alkaline comet assay. Note: Photomicrographs of comet classes (Class 0: undamaged to Class 4: maximally damaged).

After the removal of the coverslips, the slides were submersed in freshly prepared cold $\left(4^{\circ} \mathrm{C}\right)$ lysing solution (2.5 M NaCl, $100 \mathrm{mM}$ EDTA-2Na, $10 \mathrm{mM}$ Tris-HCl, and pH $10-10.5$ with $1 \%$ Triton X-100 added just prior to use) for at least $1 \mathrm{~h}$ and then placed on a horizontal electrophoresis unit. The DNA was allowed to unwind for $40 \mathrm{~min}$ in the electrophoresis running buffer solution $(0.3 \mathrm{~mol} / \mathrm{L}$ $\mathrm{NaOH}$ and $1 \mathrm{mmol} / \mathrm{L} \mathrm{Na} 2$ EDTA, $\mathrm{pH}>13$ ) at an ambient temperature of $4^{\circ} \mathrm{C}$. Following electrophoresis, the slides were stained with ethidium bromide $(2 \mu \mathrm{L} / \mathrm{mL}$ undistilled $\mathrm{H}_{2} \mathrm{O}, 70 \mu \mathrm{L} /$ slide), covered with a coverslip, and visualized using an epifluorescence microscope (Nikon, Tokyo, Japan) equipped with a rhodamine filter (excitation wavelength: $546 \mathrm{~nm}$, barrier filter: $580 \mathrm{~nm}$ ). Then the images of 100 randomly chosen nuclei ( 50 cells from each of two replicate slides) were analyzed visually. Each image was classified according to the intensity of fluorescence in the comet tail, which was rated from 0 (undamaged) to 4 (maximally damaged; Figure 1); thus, the total score of two replicate slides was 0-400 AU. All procedures were performed by the same biochemistry staff members, and DNA damage in the lymphocytes was evaluated by a single observer blind to sample group.

\section{Statistical analysis}

All data analyses were conducted using SPSS version 20.0 (IBM, Armonk, NY, USA). Numerical data (eg, oxidative/ antioxidative status parameters; TOS; TAS; OSI; UTS2R, MDA, and CAT levels; and lymphocyte DNA damage) were expressed as means \pm standard deviations, whereas categorical variables were expressed as numbers of patients (n). Intergroup comparisons (controls vs patients) were made using chi-square and Mann-Whitney $U$ tests as appropriate. One-way analysis of variance was used to assess the numerical data of migraine patients grouped by MIDAS scores (intragroup comparisons) that were normally distributed as confirmed by the Kolmogorov-Smirnov $Z$ test. Correlations between numerical data (CAT and lymphocyte DNA damage) and nonparametric data that were not normally distributed (MIDAS scores) were evaluated with Spearman's rank correlation coefficient (rho) tests. $P<0.05$ was considered to indicate statistical significance.

\section{Results}

Among the 40 patients included in the present study, the mean age was $33.20 \pm 9.38$ years (age range: $21-55$ years), and $26(65 \%)$ were females. Among the 40 healthy volunteers, the mean age was $33.30 \pm 9.40$ years (age range: $19-56$ years), and $24(60 \%)$ were females. There were no significant differences between the patient and control groups in terms of age $(P=0.954)$ or $\operatorname{sex}(P=0.768)$. Mean plasma TOS values were significantly higher in the patient group than in the control group $(P=0.007)$. Similarly, plasma lymphocyte DNA damage, MDA levels, and OSI values were significantly higher in the patient group than in the control group $(P<0.001)$, whereas plasma TAS and CAT and UTS2R levels were significantly lower in the patient group than in the control group $(P<0.001)$. 
Table I Demographic data and plasma measures of 40 adult patients with migraine and 40 healthy controls

\begin{tabular}{|c|c|c|c|}
\hline Characteristics & $\begin{array}{l}\text { Control } \\
\text { group } \\
n=40\end{array}$ & $\begin{array}{l}\text { Patients with } \\
\text { migraine } \\
n=40\end{array}$ & $P$-value \\
\hline Age (years) & $33.30+9.40$ & $33.20+9.38$ & 0.953 \\
\hline Sex (female/male) & $24 / 16$ & $26 / 14$ & 0.768 \\
\hline UTS2R (ng/mL) & $28.15 \pm 11.20$ & $11.16 \pm 4.86$ & $<0.001$ \\
\hline CAT (IU/mL) & $0.73 \pm 0.17$ & $0.44 \pm 0.18$ & $<0.001$ \\
\hline TAS (mmol Trolox ${ }^{\circledR}$ equiv./L) & $2.29 \pm 1.30$ & $1.18 \pm 0.68$ & $<0.001$ \\
\hline TOS $\left(\mu \mathrm{mol} \mathrm{H}_{2} \mathrm{O}_{2}\right.$ equiv./L) & $34.45 \pm 9.08$ & $44.75 \pm 16.74$ & 0.007 \\
\hline OSI (AU) & $1.70 \pm 0.60$ & $4.43 \pm 2.29$ & $<0.001$ \\
\hline MDA (nmol/L) & $0.59 \pm 0.07$ & $0.78 \pm 0.09$ & $<0.001$ \\
\hline DNA damage (arbitrary units) & $23.81 \pm 10.15$ & $43.5 I \pm 13.93$ & $<0.001$ \\
\hline
\end{tabular}

Notes: Data are presented as mean \pm SD or $n$. Inter-group comparisons (controls vs patients) were analyzed by chi-square and Mann-Whitney $U$ tests where appropriate. Abbreviations: CAT, catalase; MDA, malondialdehyde; $n$, numbers of patients; OSI, oxidative stress index; SD, standard deviation; TOS, total oxidant status, TAS, total antioxidant status; Trolox ${ }^{\circledast}$, 6-hydroxy-2,5,7,8-tetramethylchroman-2carboxylic acid; UTS2R, urotensin 2 receptor.

Table 1 presents comparisons of the patient and control groups in terms of demographic characteristics, UTS2R levels, lymphocyte DNA damage, oxidative stress parameters (MDA levels, TOS, OSI), and antioxidant levels (TAS and CAT levels). When patients were grouped according to migraine-related disability based on MIDAS score, there were significant differences among the three groups in mean plasma lymphocyte DNA damage and CAT levels (betweengroup comparisons for all three groups, $P<0.001$ and $P=0.04$, respectively; Table 2 and Figures 2 and 3). Mean levels of plasma lymphocyte DNA damage increased in proportion to the disability of migraine, such that the MIDAS-III group had higher levels than the MIDAS-II group $(45.02 \pm 10.15$ and 24.48 \pm 6.06 , respectively; Figure 2) and the MIDAS-IV group, which included patients with the most severe disability, had the highest mean levels (51.95 \pm 10.88 ; Figure 2).
There were no significant differences among the three groups in terms of TOS, MDA levels, OSI, TAS, or UTS2R levels ( $P=0.504, P=0.841, P=0.773$, and $P=0.401$, respectively; Table 2). MIDAS scores were positively correlated with lymphocyte DNA damage levels (rho $=0.704 ; P<0.001$ ), but neither of these factors was significantly related to CAT levels (rho $=-0.155 ; P=0.341$ ).

\section{Discussion}

The present study is the first in vivo clinical trial to simultaneously investigate UTS2R levels, oxidative stress parameters, and oxidative stress-related DNA damage in patients with varying degrees of migraine severity during the ictal phase using MIDAS scores. In addition, the alkaline comet method, which has high specificity and sensitivity for determining DNA damage in human lymphocytes, was used to assess DNA damage. The present study demonstrated significant changes in lymphocyte DNA damage, TOS, TAS, CAT and MDA levels, and OSI values in migraine patients throughout the course of the attack period compared to the control group.

The key findings of the present study are that lymphocyte DNA damage, TOS, MDA levels, and OSI values were significantly higher in the patient group than in the control group. Recent clinical data implicate that oxidative stress and/or decreased antioxidant defenses occur in patients with migraine attack. Moreover, repeated and prolonged (usually lasting for more than 72 hours) episodes of migraine may further increase brain oxidative stress and result in progressive transformation process, called chronic migraine. ${ }^{21}$ The role of oxidative stress-induced acute inflammatory responses in patients with headache attacks arising from migraine has been reported in several clinical studies. ${ }^{1,5,6,22-24}$ For example, migraine patients exhibit increased TOS and OSI values ${ }^{1,22}$

Table 2 Comparisons of plasma measures in 40 adult patients classified according to severity of migraine using the MIDAS score

\begin{tabular}{lllll}
\hline Characteristics & $\begin{array}{l}\text { MIDAS-II } \\
\text { group } \\
\mathbf{n = 8}\end{array}$ & $\begin{array}{l}\text { MIDAS-III } \\
\text { group } \\
\mathbf{n}=\mathbf{I 7}\end{array}$ & $\begin{array}{l}\text { MIDAS-IV } \\
\text { group } \\
\mathbf{n}=\mathbf{I 5}\end{array}$ \\
\hline UTS2R $(\mathrm{ng} / \mathrm{mL})$ & $10.56 \pm 2.14$ & $10.09 \pm 4.00$ & $12.70 \pm 6.41$ & 0.401 \\
CAT $(\mathrm{IU} / \mathrm{mL})$ & $0.35 \pm 0.19$ & $0.53 \pm 0.19$ & $0.38 \pm 0.12$ & 0.040 \\
TAS $\left(\mathrm{mmol}\right.$ Trolox ${ }^{\circledR}$ equiv./L) & $1.37 \pm 1.33$ & $1.14 \pm 0.42$ & $1.13 \pm 0.43$ & 0.773 \\
TOS $\left(\mu \mathrm{mol} \mathrm{H}_{2} \mathrm{O}_{2}\right.$ equiv./L) & $45.41 \pm 18.18$ & $46.46 \pm 13.51$ & $42.48 \pm 19.94$ & 0.504 \\
OSI $(\mathrm{AU})$ & $4.34 \pm 2.37$ & $4.55 \pm 1.90$ & $4.35 \pm 2.77$ & 0.792 \\
MDA (nmol/L) & $0.79 \pm 0.08$ & $0.79 \pm 0.10$ & $0.77 \pm 0.09$ & 0.841 \\
DNA damage (arbitrary units) & $24.48 \pm 6.06$ & $45.02 \pm 10.15$ & $51.95 \pm 10.88$ & $<0.001$ \\
\hline
\end{tabular}

Notes: Data are presented as mean \pm SD or $\mathrm{n}$. Intra-group comparisons (MIDAS groups) were analyzed by the one-way analysis of variance test. MIDAS-II, mild disability, (score, 6-10); MIDAS-III, moderate disability, (score, II-20); MIDAS-IV, severe disability, (score, >20).

Abbreviations: CAT, catalase; MDA, malondialdehyde; MIDAS, Migraine Disability Assessment Scale; n, numbers of patients; OSI, oxidative stress index; TAS, total antioxidant status; TOS, total oxidant status; Trolox ${ }^{\circledR}, 6$-hydroxy-2,5,7,8-tetramethylchroman-2-carboxylic acid; UTS2R, urotensin 2 receptor. 


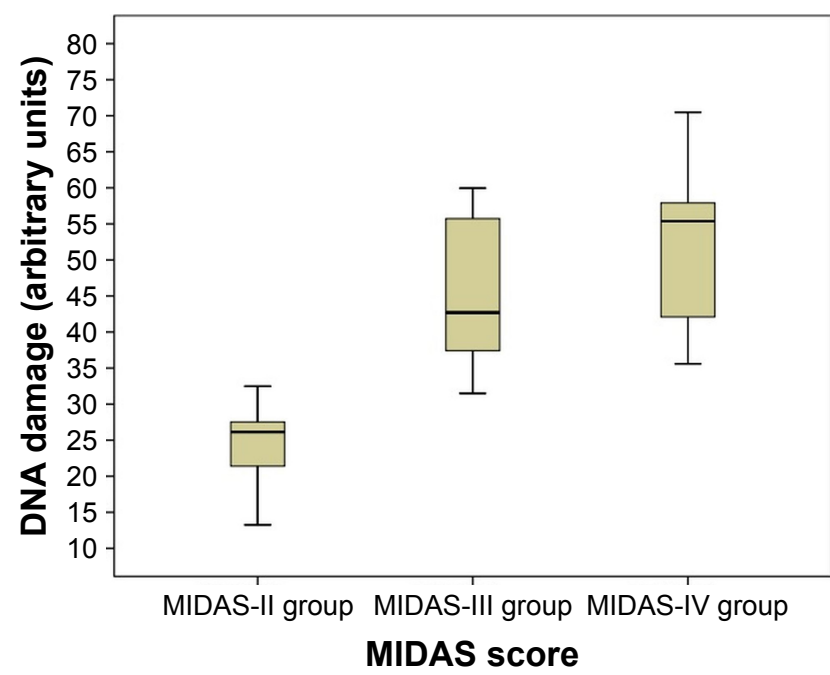

Figure 2 Plasma concentrations of markers of lymphocyte DNA damage in migraine patient groups categorized according to MIDAS score.

Notes: MIDAS-II, mild disability, (score, 6-10); MIDAS-III, moderate disability, (score, II-20); MIDAS-IV, severe disability, (score, >20).

Abbreviation: MIDAS, Migraine Disability Assessment Scale.

and Alp et al ${ }^{1}$ observed significantly higher TOS and OSI in migraine patients compared to controls. The present results regarding TOS and OSI as oxidative stress parameters are in agreement with these previous findings but contradict those of two recent clinical studies ${ }^{4,6}$ that found no difference in TOS and OSI between migraine patients and controls.

MDA is another major indicator of oxidative stress and is widely used as an index of lipid peroxidation. ${ }^{22}$ Plasma MDA levels are significantly elevated in migraine patients compared to healthy controls, ${ }^{5,22,24}$ and Yilmaz et $\mathrm{al}^{8}$ showed that plasma levels of MDA are significantly higher in migraine patients during migraine attacks compared to controls. Consistent with these findings, the present study found that

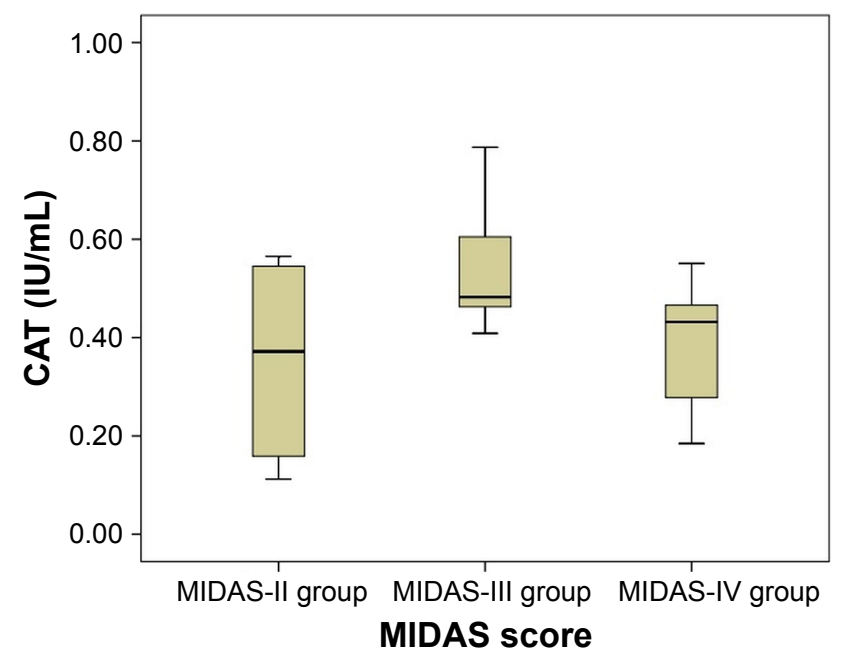

Figure 3 Plasma concentrations of CAT in migraine patient groups categorized according to MIDAS score.

Abbreviations: CAT, catalase; MIDAS, Migraine Disability Assessment Scale.
MDA levels were significantly elevated in patients during migraine attack compared to healthy controls. In accordance with the increased plasma MDA levels and TOS in migraine patients, the mean OSI value was also significantly higher. This indicates the presence of enhanced oxidative damage and ineffective antioxidant defense systems during headache attacks.

Oxidative stress-induced DNA damage and changes in or variations of DNA repair genes have been associated with the development of migraine in various clinical studies. ${ }^{4,25}$ For example, Geyik et al ${ }^{4}$ reported significantly high plasma levels of 8-OHdG, an indicator of free radical-induced DNA damage, in migraine patients. Consistent with those findings, the present study found that the mean level of plasma lymphocyte DNA damage was significantly elevated in patients with migraine attack compared to healthy controls. Thus, the development of lymphocyte DNA damage in migraine patients might be attributable to increased oxidative mechanisms.

The present study also showed that the TAS and CAT and UTS2R levels of the patient group were significantly lower than those of the control group. Plasma CAT levels and TAS are predictors of antioxidant capacity in human subjects, ${ }^{1,22}$ and several studies have reported decreased CAT levels in migraine patients. ${ }^{22,26}$ By contrast, children with migraine were found to have higher CAT levels than healthy controls. ${ }^{27}$ Several studies have demonstrated that inadequate antioxidant defense systems are associated with different types of headache..$^{22,28-30}$ Eren et $\mathrm{al}^{6}$ reported that the TAS values of migraine patients and controls were similar, and another recent study of patients with migraine also showed similar TAS in migraineurs and controls. ${ }^{4}$ However, Alp et a ${ }^{1}$ observed significant decreases in TAS in migraine patients compared to controls, which is similar to the present findings. Taken together, these findings suggest that decreases in the efficacy of the antioxidant response may reflect a severely disturbed oxidant/antioxidant balance in migraineurs, leading to increased oxidative stress.

The roles that plasma UTS2R levels play during headache attacks and headache-free periods in migraine patients have also been reported in clinical studies. ${ }^{10,11,31}$ Bicak et al ${ }^{31}$ observed lower levels of UTS2R in pediatric patients during migraine episodes compared to healthy controls, which is in agreement with the present findings. However, the present results contradict those of Geyik et al, ${ }^{10}$ who showed that UTS2R levels were higher in patients with migraine than in controls. Low UTS2R plasma levels in migraine patients relative to controls might be attributable to the role of 
UTS2R in the pathogenesis of migraine. Moreover, changes in plasma UTS2R levels may precede the vascular and muscular changes that migraineurs experience during headache attacks. The present study also observed significant differences among the patient groups categorized by MIDAS score in terms of lymphocyte DNA damage and CAT levels. The degree of lymphocyte DNA damage was positively correlated with MIDAS score, although neither of these factors was significantly related to CAT levels.

Migraine is a frequent cause of headache, in the third decade of life in particular, that results in workforce loss, significant consumption of drugs, and changes in one's daily life and social activities. ${ }^{32,33}$ The MIDAS is as an objective scoring tool that was developed to assess headache-related disability in migraineurs. ${ }^{15}$ In the present study, the highest levels of plasma lymphocyte DNA damage increased in proportion to the disability of migraine, such that the MIDAS-IV group, which was composed of patients with a severe disability, exhibited the highest level. Therefore, a greater degree of lymphocyte DNA damage may be related to more severe and frequent attacks in migraineurs. However, TOS, TAS, MDA and UTS2R levels, and OSI values were similar among the patient groups in the present study. Geyik et al ${ }^{10}$ reported a significant relationship between MIDAS score and UTS2R level, whereas the present study found that UTS2R levels were very similar in the MIDAS-II and MIDAS-III groups and only slightly higher in the MIDAS-IV group.

The present study has several limitations. First, there were relatively small numbers of patients in the migraine groups, in particular the MIDAS-II group. This may limit the reliability of the comparisons of the oxidative stress parameters and UTS2R levels among patient groups. Second, migrainerelated pain intensity was not determined using a visual analogue scale (VAS) for each patient upon arrival at the ED. Therefore, changes in oxidative/antioxidative status and the UTS2R levels could not be compared in migraineurs according to migraine-related pain severity based on VAS score. Another limitation of the present study is that lymphocyte DNA damage; TOS; TAS; MDA, CAT, and UTS2R levels; and OSI values, which may affect long-term outcomes, were not assessed during a headache-free period following the hospitalization of the patients. These issues should be considered in future studies to further clarify the effects of these parameters on patients with migraine.

\section{Conclusion}

These preliminary data indicate that the patients in the present study were exposed to potent levels of oxidative stress and that the studied markers reflected this oxidative stress. Thus, increased plasma TOS, MDA levels, lymphocyte DNA damage, and OSI values during headache attacks are more likely reflecting the burden of an unfavorable oxidant/antioxidant balance in migraine patients. Furthermore, the present study demonstrated that oxidative stress-induced lymphocyte DNA damage increased in a manner proportional to the degree of migraine-related disability as assessed by MIDAS score. Accordingly, lymphocyte DNA damage levels were positively correlated with MIDAS scores. As a result, plasma lymphocyte DNA damage might be useful for determining level of disability due to migraine in adult patients. Future controlled clinical trials conducted with larger samples are needed to support and extend these data.

\section{Disclosure}

The authors report no conflicts of interest in this work.

\section{References}

1. Alp R, Selek S, Alp SI, Taşkin A, Koçyiğit A. Oxidative and antioxidative balance in patients of migraine. Eur Rev Med Pharmacol Sci. 2010;14(10):877-882.

2. Matés JM. Effects of antioxidant enzymes in the molecular control of reactive oxygen species toxicology. Toxicology. 2000;153(1-3): 83-104.

3. Valko M, Izakovic M, Mazur M, Rhodes CJ, Telser J. Role of oxygen radicals in DNA damage and cancer incidence. Mol Cell Biochem. 2004; 266(1-2):37-56.

4. Geyik S, Altunısık E, Neyal AM, Taysi S. Oxidative stress and DNA damage in patients with migraine. J Headache Pain. 2016;17:10.

5. Tuncel D, Tolun FI, Gokce M, Imrek S, Ekerbiçer H. Oxidative stress in migraine with and without aura. Biol Trace Elem Res. 2008; 126(1-3):92-97.

6. Eren Y, Dirik E, Neşelioğlu S, Erel Ö. Oxidative stress and decreased thiol level in patients with migraine: cross-sectional study. Acta Neurol Belg. 2015;115(4):643-649.

7. Lance JW. Current concepts of migraine pathogenesis. Neurology. 1993;43(6 Suppl 3):S11-S15.

8. Yilmaz N, Aydin O, Yegin A, Tiltak A, Eren E. Increased levels of total oxidant status and decreased activity of arylesterase in migraineurs. Clin Biochem. 2011;44(10-11):832-837.

9. Kallela M, Färkkilä M, Saijonmaa O, Fyhrquist F. Endothelin in migraine patients. Cephalalgia. 1998;18(6):329-332.

10. Geyik S, Ergun S, Kuzudişli S, et al. Plasma urotensin-2 level and Thr21Met but not Ser89Asn polymorphisms of the urotensin-2 gene are associated with migraines. J Headache Pain. 2016;17:36.

11. Ames RS, Sarau HM, Chambers JK, et al. Human urotensin-II is a potent vasoconstrictor and agonist for the orphan receptor GPR14. Nature. 1999;401(6750):282-286.

12. Neri M, Frustaci A, Milic M, et al. A meta-analysis of biomarkers related to oxidative stress and nitric oxide pathway in migraine. Cephalalgia. 2015;35(10):931-937.

13. Borkum JM. Migraine triggers and oxidative stress: a narrative review and synthesis. Headache. 2016;56(1):12-35.

14. Headache Classification Committee of the International Headache Society (IHS). The International Classification of Headache Disorders, 3rd edition (beta version). Cephalalgia. 2013;33(9):629-808.

15. Stewart WF, Lipton RB, Whyte J, et al. An international study to assess reliability of the Migraine Disability Assessment (MIDAS) score. Neurology. 1999;53(5):988-994. 
16. Erel O. A new automated colorimetric method for measuring total oxidant status. Clin Biochem. 2005;38(12):1103-1111.

17. Erel O. A novel automated method to measure total antioxidant response against potent free radical reactions. Clin Biochem. 2004; 37(2):112-119.

18. Stocks J, Offerman EL, Modell CB, Dormandy TL. The susceptibility to autoxidation of human red cell lipids in health and disease. $\mathrm{Br} J$ Haematol. 1972;23(6):713-724.

19. Ohkawa H, Ohishi N, Yagi K. Assay for lipid peroxides in animal tissues by thiobarbituric acid reaction. Anal Biochem. 1979;95(2):351-358.

20. Singh NP, McCoy MT, Tice RR, Schneider EL. A simple technique for quantitation of low levels of DNA damage in individual cells. Exp Cell Res. 1988;175(1):184-191.

21. Ferroni P, Barbanti P, Della-Morte D, Palmirotta R, Jirillo E, Guadagni F. Redox mechanisms in migraine: novel therapeutics and dietary interventions. Antioxid Redox Signal. Epub 2017 Nov 21.

22. Aytaç B, Coşkun Ö, Alioğlu B, et al. Decreased antioxidant status in migraine patients with brain white matter hyperintensities. Neurol Sci. 2014;35(12):1925-1929.

23. Bolayir E, Celik K, Kugu N, Yilmaz A, Topaktas S, Bakir S. Intraerythrocyte antioxidant enzyme activities in migraine and tension-type headaches. J Chin Med Assoc. 2004;67(6):263-267.

24. Gupta R, Pathak R, Bhatia MS, Banerjee BD. Comparison of oxidative stress among migraineurs, tension-type headache subjects, and a control group. Ann Indian Acad Neurol. 2009;12(3):167-172.

25. Cetinkaya Y, Dasdemir S, Gencer M, et al. DNA repair gene variants in migraine. Genet Test Mol Biomarkers. 2014;18(8):568-573.
26. Erol I, Alehan F, Aldemir D, Ogus E. Increased vulnerability to oxidative stress in pediatric migraine patients. Pediatr Neurol. 2010;43(1): 21-24.

27. Saygi S, Erol İ, Alehan F, Yalçın YY, Kubat G, Ataç FB. Superoxide dismutase and catalase genotypes in pediatric migraine patients. $J$ Child Neurol. 2015;30(12):1586-1590.

28. Neyal M, Yimenicioglu F, Aydeniz A, et al. Plasma nitrite levels, total antioxidant status, total oxidant status, and oxidative stress index in patients with tension-type headache and fibromyalgia. Clin Neurol Neurosurg. 2013;115(6):736-740.

29. Cordero MD, Cano-García FJ, Alcocer-Gómez E, De Miguel M, Sánchez-Alcázar JA. Oxidative stress correlates with headache symptoms in fibromyalgia: coenzyme $\mathrm{Q}_{10}$ effect on clinical improvement. PLoS One. 2012;7(4):e35677.

30. Vurucu S, Karaoglu A, Paksu MS, et al. Relationship between oxidative stress and chronic daily headache in children. Hum Exp Toxicol. 2013; 32(2):113-119.

31. Bicak U, Karabiber H, Ozerol HI, Aslan M, Ilhan A, Yakinci C. Possible pathogenic link between migraine and urotensin-II. J Child Neurol. 2008;23(11):1249-1253.

32. Wöber-Bingöl C. Epidemiology of migraine and headache in children and adolescents. Curr Pain Headache Rep. 2013;17(6):341.

33. Téllez-Zenteno JF, García-Ramos G, Zermeño-Pöhls F, Velazquez A; GGSM. Demographic, clinical and comorbidity data in a large sample of 1,147 patients with migraine in Mexico City. J Headache Pain. 2005; 6(3):128-134.
Neuropsychiatric Disease and Treatment

\section{Publish your work in this journal}

Neuropsychiatric Disease and Treatment is an international, peerreviewed journal of clinical therapeutics and pharmacology focusing on concise rapid reporting of clinical or pre-clinical studies on a range of neuropsychiatric and neurological disorders. This journal is indexed on PubMed Central, the 'PsycINFO' database and CAS,

\section{Dovepress}

and is the official journal of The International Neuropsychiatric Association (INA). The manuscript management system is completely online and includes a very quick and fair peer-review system, which is all easy to use. Visit http://www.dovepress.com/testimonials.php to read real quotes from published authors. 